\title{
A Study of Clinical and Laboratory Profile of Dengue Fever in Tertiary Centre
}

\author{
Sundeep Singla ${ }^{1}$, Mamta Singla ${ }^{2}$, Sanjeev Singla ${ }^{3}$, Parmajeet Singh ${ }^{4}$, Atul Kumar $^{5}$ \\ ${ }^{1}$ Assistant Professor, Department of General Medicine, Adesh Medical College \& Hospital, Mohri, Shahabad (M), Haryana, ${ }^{2}$ Professor and Head, Department of \\ Surgery, Muzaffarnagar Medical College, Muzaffarnagar. UP, ${ }^{3}$ Associate Professor, Department of Surgery, B.P.S. Government Medical College for Women, \\ Khanpur Kalan, Sonepat (Haryana), ${ }^{4}$ Professor and Head, Department of Microbiology, Muzaffarnagar Medical College, Muzaffarnagar. UP, ${ }^{5}$ Assistant Professor, \\ Department of Microbiology, Muzaffarnagar Medical College, Muzaffarnagar. UP.
}

\section{Abstract}

Background: Dengue is an acute febrile disease in the tropical and subtropical regions. There is a steady rise in Dengue outbreaks in India. The present study describes clinical and laboratory findings of serologically confirmed hospitalized cases of dengue fever. Subjects and Methods: Prospective study was done in seropositive hospitalized adult patients in Muzaffarnagar Medical College, Muzaffarnagar, U.P. 84 patients were analyzed. Clinical features, Haematological and Biochemical parameters were noted. Results: Out of 84 patients studied, 51 were male and 33 were female. The fever was present in all patients, followed by Anorexia in 65 (77.38\%), Vomiting in $56(66.66 \%)$, Myalgia in 52 (61.90\%), Headache in 37 (44.04\%), Joint pain in 25 (29.76\%), Retrobulbar pain in 24 (28.57\%) and Rashes in 18 (21.42\%) patients. Abdominal pain was present in 11 (13.09\%), Hepatomegaly in 10 (11.90\%), Pleural effusion in 6 (7.14\%) and Ascites in 9 patients $(10.71 \%)$. Shock was present in $5(5.95 \%)$ and bleeding in $3(3.57 \%)$ patients. Significant derangement in platelet count was noted. Conclusion: The problem of Dengue fever is on continuous rise. It may be due to huge population, poor sanitation, waste management policies, lack of medical facilities in the rural population and inadequate mosquito control. So, a continuous sero-epidemiological surveillance, early diagnosis, timely and proper fluid management can reduce its complications, outbreaks and mortality.

Keywords: Dengue fever, Clinical profile, Laboratory profile, Western U.P.

Corresponding Author: Dr Atul Kumar, C - 44, Faculty Campus, Muzaffarnagar Medical College, Muzaffanagar. UP

Received: July 2019

Accepted: July 2019

\section{Introduction}

Dengue fever is an acute febrile disease in the tropical and subtropical regions. Globally, its incidence has increased in recent years. WHO estimated $50-100$ million cases every year with 5lakhs people requiring hospitalization annually. ${ }^{[1]}$ India is one of the seven countries in the South East Asian region regularly reporting the incidence of Dengue Fever (DF) / Dengue Haemorrhagic Fever (DHF) outbreaks from both urban and rural areas.

Dengue fever is caused by Aedesaegypti mosquito. Itis primary vector. Infected female mosquito transmits virus to humans. After incubation of 4-10 days, an infected mosquito is capable of transmitting the virus for the rest of life. Infected humans are the main carriers and multipliers of the virus. Period of transmission from humans to mosquitoes begins one day before the start of fever up to sixth day of illness corresponding to the viremia phase.

Dengue infection effects infants, young children and adults. It varies in severity ranging from flu like self-limiting illness to life threatening Dengue Haemorrhagic fever (DHF) and Dengue Shock Syndrome (DSS), which, if left untreated are associated with mortality as high as $20 \%$, while in hospitalized patients mortality is as low as $1 \%{ }^{[2]}$
The present study is an attempt to describe the clinical manifestations as well as laboratory findings of serologically confirmed hospitalized cases of dengue fever.

\section{Subjects and Methods}

This study was carried out from August 2017 to October 2017 in Muzaffarnagar Medical College, Muzaffarnagar (U.P.). It was a prospective hospital based study. A total of 84 adult patients diagnosed with Dengue fever were enrolled in this study. All the patients who presented with fever and found positive to any one of Dengue NS1 antigen or IgM, IgG antibodies admitted in the hospital were included. A detailed history was taken and a careful clinical examination was performed. The laboratory investigations like complete blood count (CBC), Kidney function tests (KFT), Liver function tests (LFT), Chest x-ray, ultrasound abdomen were done in the relevant patients. Blood counts were monitored regularly.

\section{Exclusion criteria}

All the patients with malaria, urinary tract infection, enteric fever, liver abscess, pneumonitis, haematological disorders, and malignancies were excluded. 


\section{Results}

524 cases of fever were admitted and treated from 1st August 2017 to 30th November 2017. Out of which 84 cases were seropositive Dengue fever cases. Out of these 84 cases, 51 cases were male and 33 cases were female. The male to female ratio was $3: 2$.

Age group effected predominantly was between 18 to 30 years. It contributed to $52.38 \%$ cases. Age group distribution is shown in [Table 1]

Table 1: Age distribution
\begin{tabular}{|l|l|l|}
\hline Age Group & No. of cases & Percentage \\
\hline $18-30$ & 44 & $52.38 \%$ \\
\hline $31-40$ & 16 & $19.04 \%$ \\
\hline $41-50$ & 15 & $17.85 \%$ \\
\hline $51-60$ & 5 & $5.95 \%$ \\
\hline Above 60 & 4 & $4.76 \%$ \\
\hline
\end{tabular}

The most common symptom was Fever in 84 (100\%) patients, followed by Anorexia in 65 (77.38\%), vomiting in $56(66.66 \%)$, Myalgia in $52(61.90 \%)$, Headache in 37 (44.04\%), Joint pain in $25(29.76 \%)$, Retrobulbar pain in 24 $(28.57 \%)$ and Rashes in $18(21.42 \%)$ patients. Abdominal pain was present in $11(13.09 \%)$, Hepatomegaly in 10 (11.90\%), Pleural effusion in $6(7.14 \%)$ and Ascites in 9 patients $(10.71 \%)$. Shock was present in $5(5.95 \%)$ and bleeding in $3(3.57 \%)$ patients as shown in [Table 2].

Table 2: Clinical Symptoms and signs

\begin{tabular}{|l|l|l|}
\hline Fever & 84 & $100 \%$ \\
\hline Headache & 37 & $44.04 \%$ \\
\hline Myalgia & 52 & $61.90 \%$ \\
\hline Retrobulbar Pain & 24 & $28.57 \%$ \\
\hline Rash & 18 & $21.42 \%$ \\
\hline Abdominal Pain & 11 & $13.09 \%$ \\
\hline Joint Pain & 25 & $29.76 \%$ \\
\hline Vomiting & 56 & $66.66 \%$ \\
\hline Bleeding & 3 & $3.57 \%$ \\
\hline Anorexia & 65 & $77.38 \%$ \\
\hline Pleural Effusion & 6 & $7.14 \%$ \\
\hline Shock & 5 & $5.95 \%$ \\
\hline Ascitis & 9 & $10.71 \%$ \\
\hline Hepatomegaly & 10 & $11.90 \%$ \\
\hline
\end{tabular}

Complete Blood Count showed leucopenia in 29 cases, leucocytosis in 10 cases while the rest had normal leucocyte count. Platelet counts were done on automated cell counter on daily basis. They were diminished below 20,000 cells/cumm in 16 patients, 20,000 to $<50,000$ in 50 patients and 50,000 to $<1,00,000$ in 18 patients as shown in [Table 3]. Average hospital stay was $4-6$ days. At the time of discharge the platelet count was 70,000-80,000 with rising trend. Death was nil in our study.

\section{Table 3: Platelet Count}

\begin{tabular}{|l|l|l|}
\hline $\begin{array}{l}\text { Platelet Count in } \\
\text { cells } / \mathbf{~ m m ~ 2 ~}\end{array}$ & Number of cases & Percentage \% \\
\hline $50,000-1,00,000$ & 18 & 21.44 \\
\hline $20,000<50,000$ & 50 & 59.54 \\
\hline $5,000<20,000$ & 16 & 19.06 \\
\hline
\end{tabular}

[Table 4] shows various serological markers evaluated. NS
1 was positive in $78.57 \%$, NS 1 and IgM were positive in $7.14 \%$ cases i.e. representing the incidence of new cases. IgG positive cases $2.38 \%$ show of old cases and IgM with NS 1 antigen positive cases can be due to early clearance of antigen.

Table 4: Dengue Serological Markers
\begin{tabular}{|l|l|l|}
\hline NS 1 & 66 & $78.57 \%$ \\
\hline NS 1 and IgM & 6 & $7.14 \%$ \\
\hline IgM / IgG & 3 & $3.58 \%$ \\
\hline IgM & 4 & $4.76 \%$ \\
\hline IgG & 2 & $2.38 \%$ \\
\hline NS 1, IgG, IgM & 2 & $2.38 \%$ \\
\hline NS 1, IgG & 1 & $1.19 \%$ \\
\hline
\end{tabular}

\section{Discussion}

Dengue is an important emerging problem in India. The epidemics of dengue fever have been reported in the post monsoon season i.e. from August to November. The peak incidence was in September and October in our study which is in accordance with other studies. ${ }^{[3,4]}$ Increase in number of dengue cases may be due to rapid unplanned urbanization, poor sanitation facilities and lack of waste management. These factors contribute to fertile breeding areas for mosquitoes.

Male to female ratio in our study is 3: 2. Various Indian studies have shown a male preponderance. ${ }^{[3]}$ This may be attributed to the outdoor activities of male, while equal sex distribution was reported by Chatterjee et al. ${ }^{[5]}$ Fever was the most common symptom (100\%). Myalgia - 52 patients $(61.90 \%)$, Headache -37 patients $(44.04 \%)$ and Joint pain 25 patients $(29.76 \%)$ were other common symptoms which is also reported from various studies from India and South East Asia. ${ }^{[6-9]}$ Abdominal pain was seen in 11 patients $(13.09 \%)$. This was is in accordance with other studies and in contrast to $62.4 \%$ reported by Daniel et al, ${ }^{[8]}$ and $64 \%$ reported by Payal Jain et al. ${ }^{[10]}$ Anorexia was present in 65 $(77.38 \%)$ and Vomiting in $56(66.66 \%)$ patients.

In our study, rashes were present in 18 (21.42\%). This was in accordance with Karoli et al, ${ }^{[11]}$ Mandal et al. ${ }^{[12]}$ if it is observed in the initial phase of illness, it is diagnostic of Dengue fever.

Serositis in the form of pleural effusion and ascites from capillary leak are being frequently reported in various studies. In our study, only $6(7.14 \%)$ cases of Pleural effusion and $9(10.71 \%)$ of Ascites were confirmed radiologically. It was self-limiting and subsided within 2-3 weeks of recovery.

In present study, thrombocytopenia was the most common abnormal laboratory finding observed. Thrombocytpenia with platelet count less than 1,00,000 cells/cumm was seen in $21.44 \%$, less than 50,000 cells/cumm in $59.54 \%$ and less than 20,000 cells/cumm in $19.06 \%$ patients. In Seema A et al, ${ }^{[3]}$ Ageep $A \quad K$ et $a l,{ }^{[13]}$ and Mittal $\mathrm{H}$ et $a l,{ }^{[14]}$ thrombocytopenia was most common laboratory finding though the incidence varied marginally.

In present study, most common type of serology test which was positive is NS 1 i.e 66 patients (78.57\%). NS 1 and IgM 
was positive in 6 patients $(7.14 \%), \operatorname{IgM} / \operatorname{IgG}$ in 3 patients $(3.58 \%)$, $\operatorname{IgM}$ in 4 patients $(4.76 \%), \operatorname{IgG}$ in 2 patients $(2.38 \%)$ and NS $1, \operatorname{IgG}, \operatorname{IgM}$ in 2 patients $(2.38 \%)$. This is in accordance with other studies. ${ }^{[15,16]}$

\section{Conclusion}

The problem of Dengue fever is on continuous rise. It may be due to huge population, poor sanitation, waste management policies, lack of medical facilities in the rural population and inadequate mosquito control. So, a continuous sero-epidemiological surveillance, early diagnosis, timely and proper fluid management can reduce its complications, outbreaks and mortality.

\section{References}

1. World Health Organization. Dengue and severe dengue. Fact sheet no. 117, March 2014. Geneva: WHO, 2014 http:/www.who.int/mediacentre/factsheets/fs117/en/-accessed 16 March 2014

2. World Health Organization and Tropical Diseases Research. Dengue: Guidelines for diagnosis, treatment, prevention and control. Geneva: World Health Organization. 2009.

3. Seema A, Singh V, Kumar S et al. The Changing Clinical Spectrum of Dengue Fever in 2009 Epidemic in North India. Journal of Clinical and Diagnostic Research 2012; 6: 999-1002.

4. Kumar A, Rao R, Pandit V et al. Clinical manifestation and trend of dengue cases admitted in tertiary care hospital, Udupi, Karnataka. Indian J Community Med 2010; 35: 386-91.

5. Chatterjee N, Mukhopadhyay M, Ghosh S et al. An observational study of dengue fever in a tertiary care hospital of eastern India. JAPI 2014; 62:224-7.

6. Srikiatkhachorn A, Gibbons RV, Green S, Libraty DH, Thomas SJ, et al. Dengue hemorrhagic fever: the sensitivity and specificity of the world health organization definition for identification of severe cases of dengue in Thailand, 1994-2005. Clin Infect Dis 2010; 50:11351143.

7. Mohan D K, Shiddappa, Dhananjaya M. A Study of Clinical Profile of Dengue Fever in a Tertiary Care Teaching Hospital. SchJ App Med Sci 2013; 1:280-282.

8. Rachel Daniel, Rajamohanan, Aby Zachariah Philip. A study of clinical profile of dengue fever in Kollam, Kerala, India. Dengue Bulletin 2005; 29:197-202.

9. Munde DD, Shetkar UB. Clinical Features and Haematological Profile of Dengue Fever. Indian J Appl Res 2013; 3:131-132.

10. Payal Jain, DheerendraKuber, Ajay K Garg, GD Sharma, AK Agrawal. Manifestation of dengue fever : A hospital based study. J Ind Academy of Clin Med 2015;16(3\&4):204-8.

11. Karoli R, Fatima J, Siddiqi $Z$ et al. Clinical profile of dengue infection at a teaching hospital in North India. J Infect DevCtries 2012; 6: 551-4.

12. Mandal SK, Ganguly J, KoelinaSil et al. Clinical profiles of dengue fever in a teaching hospital of eastern India. Nat $\mathrm{J}$ Med Res 2013;3:173-176.

13. Ageep AK, Malik AA, Elkarsani MS. Clinical presentations and laboratory findings in suspected cases of dengue virus. Saudi Med J. 2006;27(11):1711-3.

14. Mittal H, Faridi MM, Arora SK, Patil R. Clinicohematological profile and platelet trends in children with dengue during 2010 epidemic in north India. Indian J Pediatr. 2012;79(4):467-71.

15. Khan SA, Dutta P, Topno R, Soni M, Mahanta J. Dengue Outbreak in Hilly State of Arunachal Pradesh in Northeast India. The Scientific World J. 2014 (2014):Article ID 584093.

16. Yagnik H. Chhotala, Chetal M. Suva. A study of clinical profile of dengue fever in a tertiary care hospital of Jamnagar, Gujarat, India. Int J Res Med Sci. 2016 Oct;4(10):4500-4504

Copyright: (C) the author(s), 2019. It is an open-access article distributed under the terms of the Creative Commons Attribution License (CC BY 4.0), which permits authors to retain ownership of the copyright for their content, and allow anyone to download, reuse, reprint, modify, distribute and/or copy the content as long as the original authors and source are cited.

How to cite this article: Singla S, Singla M, Singla S, Singh P, Kumar A. A Study of Clinical and Laboratory Profile of Dengue Fever in Tertiary Centre. Asian J. Med. Res. 2019;8(2):ME23-ME25.

DOI: dx.doi.org/10.21276/ajmr.2019.8.2.ME8

Source of Support: Nil, Conflict of Interest: None declared. 